\title{
Analysis of Vitamin D Levels on Bronchiectasis Severity
}

\author{
Yacob Arawamin Batkunde ${ }^{1}$, Muhammad Ilyas ${ }^{1,2}$, Irawaty Djaharuddin ${ }^{1}$, \\ Nur Ahmad Tabri' ${ }^{1,2}$, Harun Iskandar ${ }^{1,2}$, Arif Santoso ${ }^{1}$ \\ ${ }^{1}$ Departement Pulmonology and Respiratory Medicine Faculty of Medicine, Hasanuddin University/ \\ Wahidin Sudirohusodo Hospital, Makassar \\ 2 Departement Pulmonology and Respiratory Medicine Faculty of Medicine, Hasanuddin University, \\ Makassar
}

\section{ABSTRACT}

Background: Bronchiectasis is a chronic disease caused by repeated infection and inflammation of the bronchial walls. Vitamin D plays a role secretion of antimicrobial peptide and inhibits release of pro-inflammatory cytokines in the lungs. Vitamin D deficiency is associated with exacerbations, severity and decreased lung function in bronchiectasis. Several studies have found an association between vitamin D levels and bronchiectasis severity.

Method: This study used cross-sectional study design with consecutive sampling method on bronchiectasis patients who enrolled outpatient and inpatient at Wahidin Sudirohusodo hospital in February - May 2020. All research procedures obtained the approval of the Health Research Ethics Commission, Medicine faculty, Hasanuddin University Makassar.

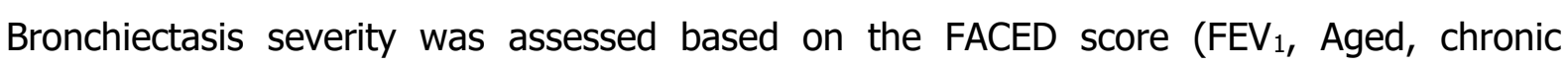
Colonization by Pseudomonas aeuroginosa, radiological Extension of the disease, Dyspnea). Levels of vitamin D serum (250HD) were measured using the ELISA method.

Results: The study subjects were 44 patients, consisting of $61.4 \%$ male and $38.6 \%$ female. Most of the bronchiectasis patients in this study were mild (77.3\%) based on the FACED score, $15.9 \%$ moderate and $6.8 \%$ severe. As many as $77.3 \%$ of patients had vitamin D deficiency and insufficiency as much as $9.1 \%$. All patients with moderate-severe FACED scores had vitamin D deficiency. The correlation between vitamin D levels and FACED scores showed a positive significant.

Conclusion: There is a positive correlation between low vitamin $D$ levels and the severity of bronchiectasis $(\mathrm{P}=0.04)$

Keywords: bronchiectasis, vitamin D, FACED score, severity

*Correspondence: Yacob Arawamin Batkunde - yacobbatkunde@gmail.com

Submitted: February $4^{\text {th }}$ 2021, Accepted: February 11 ${ }^{\text {th }} 2021$, Published: February $28^{\text {th }} 2021$ 


\section{INTRODUCTION}

Bronchiectasis is a chronic disease with high morbidity. Abnormal airway dilatation in bronchiectasis causes impaired mucociliary clearance that leads to mucus buildup, recurrent infection and inflammation. The clinical symptoms of bronchiectasis are similar to those of other lung diseases and require additional radiological examination using high resolution computed tomography scan (HRCT) thorax. ${ }^{1-3}$ The parameters to assess the severity of bronchiectasis were included in bronchiectasis severity index (BSI) or FACED (Forced expiratory volume in one second/FEV 1 , Aged, Chronic colonization by Pseudomonas aeuroginosa, radiological Extension of the disease, Dyspnea) scoring systems. ${ }^{4-6}$

Vitamin $D$ plays a role in suppressing inflammation and regulating antimicrobial peptide secretion in respiratory system. Enzyme 1a-hydroxylase plays a role in the activation of vitamin $D$ expressed by airway epithelium, alveolar macrophages, dendritic cells and lymphocytes. ${ }^{7-9}$ Vitamin $D$ deficiency is often associated with high colonization, exacerbations and severity rates of bronchiectasis. Vitamin D deficiency can occur due to insufficient sunlight exposure and nutrient intake, liver disease, kidney disease and loss of vitamin $\mathrm{D}$ binding protein. ${ }^{8-10}$

Vitamin D deficiency is often associated with high colonization, exacerbations and severity rates of bronchiectasis. ${ }^{10}$ Vitamin $\mathrm{D}$ deficiency can occur due to insufficient sunlight exposure and nutrient intake, liver disease, kidney disease and loss of vitamin $\mathrm{D}$ binding protein. ${ }^{8,9}$.

Several studies have found a correlation between vitamin $D$ levels and bronchiectasis. As for the studies in Indonesia regarding the correlation between vitamin $D$ levels and respiratory diseases including bronchiectasis are still limited. This is the author's background for the to research the effect of vitamin $D$ on the severity of bronchiectasis.

\section{METHOD}

A cross-sectional study was conducted. This study was performed in the department of pulmonology and respiratory medicine of Wahidin Sudirohusodo General Hospital and included 44 subjects that met the inclusion criteria. Written and verbal informed consent was obtained from every participants according to approval of the Health Research Ethics Committee of the Faculty of Medicine, Hasanuddin University No: 191/UN4.6.4.5.31/PP36/2020. 
The inclusion criteria for this study is a male or female HRCT confirmed bronchiectasis patients $\geq 18$ years of age and able to complete spirometry test. The severity of bronchiectasis was assessed based on FACED score (FEV1, Aged, chronic Colonization by Pseudomonas aeuroginosa, radiological Extension of the disease, Dyspnea). Vitamin D (25OHD) serum levels was measured using the ELISA method. The exclusion criteria were bronchiectasis patients with incomplete examination results.

Statistical analyses were completed using the SPSS statistical software package (version 24.0). The obtained results will be displayed in a narrative equipped with tables and graphs.

\section{RESULT}

A total of 44 subjects consisting of 27 men (61.4\%) and 17 women (38.6\%) with the largest proportion of age ranging from 50 to 59 years old (31.8\%). Microbial culture showed colonization in 20 patients (45.4\%), i.e. Acinetobacter baumanii (6.8\%), Klebsiella pneumonia (6.8\%), and Pseudomonas aeruginosa (4.5\%). Lung lesion extension were based on the number of affected lobes, 34 patients with $\leq 2$ affected lobes (77.3\%) and 10 patients with $>2$ lobes of $(22.7 \%)$.

Table 1. Characteristics of The Participants

\begin{tabular}{|c|c|c|}
\hline Variables & $\mathbf{N}$ & $\%$ \\
\hline \multicolumn{3}{|l|}{ Sex } \\
\hline Male & 27 & 61.4 \\
\hline Female & 17 & 38.6 \\
\hline \multicolumn{3}{|l|}{ Age (years) } \\
\hline $18-29$ & 3 & 6.8 \\
\hline $30-39$ & 7 & 15.9 \\
\hline $40-49$ & 6 & 13.6 \\
\hline $50-59$ & 14 & 31.8 \\
\hline $60-69$ & 9 & 20.5 \\
\hline$\geq 70$ & 5 & 11.4 \\
\hline \multicolumn{3}{|l|}{ Body Mass Index (BMI) } \\
\hline Underweight & 16 & 36.4 \\
\hline Normal & 16 & 36.4 \\
\hline Overweight & 12 & 27.3 \\
\hline \multicolumn{3}{|l|}{$\mathrm{FEV}_{1} / \mathrm{FEV}_{1}(\%)$} \\
\hline$\geq 50 \%$ & 24 & 54.5 \\
\hline$<50 \%$ & 20 & 45.5 \\
\hline
\end{tabular}


Table 1. Characteristics of The Participants (cont.)

\begin{tabular}{lcc}
\hline \multicolumn{1}{c}{ Variables } & N & \% \\
\hline Colonization & 24 & 54.5 \\
None & 3 & 6.8 \\
Acinetobacter baumanii & 3 & 6.8 \\
Klebsiella pneumonia & 2 & 4.5 \\
Pseudomonas aeruginosa & 12 & 27.3 \\
Other microorganisms & & \\
Lung lesion extension (affected lobes) & 34 & 77.3 \\
$\leq 2$ & 10 & 22.7 \\
$>2$ & & \\
mMRC & 29 & 65.9 \\
$\leq 2$ & 15 & 34.1 \\
$>2$ & & 77.3 \\
FACED Score & 34 & 15.9 \\
Mild & 7 & 6.8 \\
Moderate & 3 & 13.6 \\
Severe & & 9.1 \\
Vitamin D & & 77.3 \\
Normal $(\geq 30 \mathrm{ng} / \mathrm{ml})$ & 6 &
\end{tabular}

Table 2. The Relationship Between Characteristics and Vitamin D Levels

\begin{tabular}{|c|c|c|c|c|c|}
\hline \multirow{2}{*}{ Characteristics } & \multicolumn{3}{|c|}{ Vitamin D Levels } & \multirow[b]{2}{*}{ Total } & \multirow[b]{2}{*}{$\mathbf{P}$} \\
\hline & Deficiency & Insufficiency & Normal & & \\
\hline \multicolumn{6}{|l|}{ Sex } \\
\hline Male & $19(55.9 \%)$ & $3(75 \%)$ & $5(83.3 \%)$ & $27(61.4 \%)$ & \multirow{2}{*}{0.016} \\
\hline Female & $15(44.1 \%)$ & $1(25 \%)$ & $1(16.7 \%)$ & $17(38.6 \%)$ & \\
\hline \multicolumn{6}{|l|}{ Body Mass Index (BMI) } \\
\hline Underweight & $10(29.4 \%)$ & $2(50 \%)$ & $4(66.7 \%)$ & $16(36.4 \%)$ & \multirow{3}{*}{0.010} \\
\hline Normal & $13(38.2 \%)$ & $1(25 \%)$ & $2(33.3 \%)$ & $16(36.4 \%)$ & \\
\hline Overweight & $11(32.4 \%)$ & $1(25 \%)$ & $0(0.0 \%)$ & $12(27.3 \%)$ & \\
\hline \multicolumn{6}{|l|}{$\mathrm{FEV}_{1}$} \\
\hline$<50 \%$ & $17(50 \%)$ & $0(0.0 \%) 4$ & $3(50 \%)$ & $20(45.5 \%)$ & \multirow{2}{*}{0.923} \\
\hline$\geq 50 \%$ & $17(50 \%)$ & $(100 \%)$ & $3(50 \%)$ & $24(54.5 \%)$ & \\
\hline \multicolumn{6}{|l|}{ Age (years) } \\
\hline$<70$ & $30(88.2 \%)$ & $3(75 \%)$ & $6(100 \%)$ & $39(88.6 \%)$ & \multirow{2}{*}{0.853} \\
\hline$\geq 70$ & $4(11.8 \%)$ & $1(25 \%)$ & $0(0.0 \%)$ & $5(11.4 \%)$ & \\
\hline \multicolumn{6}{|l|}{ Colonization } \\
\hline None & 32 94.1\%) & $4(100 \%)$ & $6(100 \%)$ & $42(95.5 \%)$ & \multirow{2}{*}{0.420} \\
\hline P. aeruginosa & $2(5.9 \%)$ & $0(0.0 \%)$ & $0(0.0 \%)$ & $2(4.5 \%)$ & \\
\hline
\end{tabular}


Table 2. The Relationship Between Characteristics and Vitamin D Levels (cont.)

\begin{tabular}{lccccc}
\hline \multirow{2}{*}{ Characteristics } & \multicolumn{3}{c}{ Vitamin D Levels } & \multirow{2}{*}{ Total } & \multirow{2}{*}{ P } \\
\cline { 2 - 4 } & Deficiency & Insufficiency & Normal & & \\
\hline $\begin{array}{l}\text { Lung lesion extension } \\
\leq 2 \text { lobes }\end{array}$ & $2573.5 \%)$ & $3(75 \%)$ & $6(100 \%)$ & $34(77.3 \%)$ & 0.268 \\
$>2$ lobes & $9(26.5 \%)$ & $1(25 \%)$ & $0(0.0 \%)$ & $10(22.7 \%)$ & \\
mMRC & & & & & \\
$\leq 2$ & $23(67.6 \%)$ & $3(75 \%)$ & $3(50 \%)$ & $29(65.9 \%)$ & 0.442 \\
$>2$ & $11(32.4 \%)$ & $1(25 \%)$ & $3(50 \%)$ & $15(34.1 \%)$ & \\
\hline
\end{tabular}

Table 3. The Relationship Between Bronchiectasis Severity Based On FACED Score and Vitamin D Levels

\begin{tabular}{lccccc}
\hline \multirow{2}{*}{ FACED Score } & \multicolumn{3}{c}{ Vitamin D Levels } & \multirow{2}{*}{ Total } & \multirow{2}{*}{ P } \\
\cline { 2 - 4 } & Deficiency & Insufficiency & Normal & & \\
\hline Mild & $24(70.6 \%)$ & $4(100 \%)$ & $6(100 \%)$ & $34(77.3 \%)$ & \multirow{2}{*}{0.04} \\
Moderate-Severe & $10(30.4 \%)$ & $0(0.0 \%)$ & $0(0.0 \%)$ & $10(22.7 \%)$ & \\
\hline
\end{tabular}

The severity of the disease was classified based on the FACED score, mild bronchiectasis was found in 34 patients (77.3\%), moderate bronchiectasis was found in 7 patients $(15.9 \%)$, and severe bronchiectasis in 3 patients (6.8\%). In blood serum examination, normal vitamin $D$ levels was found in 6 patients (13.6\%), insufficiency in 4 patients $(9.1 \%)$, and deficiency in 34 patients (77.3\%). The data is illustrated on table 1 below.

Table 2 depicts the relationship between characteristics of the study participants and vitamin D levels. We found statistically significant relationships between vitamin $D$ levels and both sex and nutritional status in bronchiectasis patients $(P<0.05)$. It indicates that vitamin $D$ levels in women were lower than in men. In addition, higher rates of normal and insufficient vitamin D levels were found in patients with lower BMI than those with normal BMI.

Based on Table 2 also showed no significant association between vitamin $D$ levels and the parameters of the FACED score $\left(\mathrm{FEV}_{1}\right.$, age, colonization, lesion area and $\mathrm{mMRC}$ score) with $P>0.05$. It means that the level of vitamin D statistically has no positive or negative correlation with the FACED score parameters.

Table 3 showed that in 44 subjects, we found that all patients with moderate-severe FACED scores had vitamin $D$ deficiency. The association between vitamin D levels and FACED scores in bronchiectasis patients was assessed by a non-parametric test that resulted in $P=0.04$, which means that there is a significant positive 
relationship between vitamin $D$ levels and FACED score.

\section{DISCUSSION}

Fourty four patients with bronchiectasis were included in the study. Twenty seven were male $(61.4 \%)$ and 17 were female (38.6\%). This is consistent with a study by Bhatta et al which found that the incidence of bronchiectasis was more in men than women, $70 \%$ and $30 \%$ respectively. ${ }^{11}$ Several studies found different results, Habesoglu et al and Martınez-Garcia et al reported higher incidence in women compared to men. ${ }^{12,13}$

The different results found in each sex can be caused by several factors, including the higher number of smokers in men, exposure to other harmful gases or particles, differences in the structure of respiratory tract, microbial composition and function. ${ }^{5,14}$ Higher smoking rates in men in several Asian countries including Indonesia may be associated with a higher incidence of bronchiectasis in men than women. ${ }^{11,15}$

This study reported the highest incidence of bronchiectasis in 50-59 years age group (31.8\%). Several studies had also shown that the incidence rate is the highest in the same age range. ${ }^{12}$ The incidence of bronchiectasis increased substantially with increasing age. The increasing prevalence of bronchiectasis in the older age group is associated with longer and higher exposure to dust/ harmful particles. ${ }^{16}$

This study did not find any statistically significant relationship between vitamin $D$ levels and $\mathrm{FEV}_{1}$. It may occured because the $\mathrm{FEV}_{1}$ examination was not carried out regularly, making it difficult to evaluate the relationship between vitamin $D$ levels and the decrease in $\mathrm{FEV}_{1}$. Studies by Ilyas et al and Malinovschi et al also did not find any significant relationship between vitamin $D$ levels and the degree of obstruction $\left(\mathrm{FEV}_{1}\right) \cdot{ }^{17,18} \mathrm{~A}$ study by Chalmers et al found a greater decrease in $\mathrm{FEV}_{1}$ in bronchiectasis patients with vitamin $D$ deficiency compared to the normal group because the study assessed FEV $\mathrm{F}_{1}$ over 3 years of observation. Several studies also found a significant correlation after several years of observation. ${ }^{10}$

Microbial culture reported colonization occurred in 20 patients (45.4\%), i.e. Acinetobacter baumanii and Klebsiella pneumonia $6.8 \%$ each, and Pseudomonas aeruginosa $4.5 \%$. It is similar with studies by Bhatta et al and Bopaka et al which reported low colonization of microorganisms, $50 \%$ and $35 \%$ respectively. Colonization easily occurs due to permanent 
changes in airway structures, impaired mucociliary clearance, increased mucus viscosity and repeated exposure to harmful gases/ particles. In addition, a history of antibiotics use in the previous health facility may contribute to negative culture. ${ }^{19-21}$ In this study, it could be possible that there was a history of antibiotics administration from the previous hospital, leading to many negative culture results.

The proportion of vitamin $D$ levels was found to be $77.3 \%$ for deficiency, $13.6 \%$ for normal level and $9.1 \%$ for insufficiency. This study is somewhat different from several studies in Indonesia. Studies by Suryadinata et al and Widyaswari et al found high rates of vitamin $D$ deficiency and insufficiency. ${ }^{22,23} \mathrm{~A}$ study by Saragih JP et al on tuberculosis (TB) patients in Medan found a high rate of vitamin D insufficiency, but did not find which patients had vitamin D deficiency. ${ }^{24}$ Other studies have shown a low vitamin $D$ concentrations in the population in Indonesia even though they get enough sunlight exposure. It showed that there are various factors that affect vitamin $D$ levels, especially as the dietary sources are limited. ${ }^{22}$

FACED score is an instrument to evaluate the severity and prognosis of bronchiectasis through an analysis of five parameters. FACED score was developed specifically to predict mortality rate within five years after treatment for various etiologies, thus providing a rapid assessment of bronchiectasis severity in the early stage of the disease. ${ }^{6}$ According to the FACED score, we found that 34 patients had mild bronchiectasis (77.3\%) and 10 patients had moderate-severe bronchiectasis (22.3\%). The number of patients with moderate-severe category in this study was less due to the lack of subjects with high score parameters, such as age of $\geq 70$ years and $\mathrm{FEV}_{1}$ $\leq 50 \%$, thus affecting the final score of FACED.

In this study, we reported that all patients with moderate-severe FACED scores were accompanied by vitamin $D$ deficiency. This study showed a statistically significant relationship between vitamin $D$ levels and FACED scores $(P=0.04)$. Vitamin $D$ deficiency is one of the risk factors that aggravate bronchiectasis because it may increase the inflammatory response and susceptibility to recurrent infections in the lungs. Vitamin $D$ deficiency that accompanies bronchiectasis is often caused by lack of sunlight exposure and nutrient intake. ${ }^{10,25}$ Therefore, vitamin $D$ levels evaluation can be considered as an indicator of the inflammatory response and the severity of bronchiectasis. ${ }^{25,26}$ Several studies had 
also demonstrated the benefit of vitamin D supplementation for patients with bronchiectasis, asthma, chronic obstructive pulmonary disease (COPD) and pulmonary tuberculosis. ${ }^{25}$

A study by Ferri et al., assessing the association of vitamin $D$ with bronchiectasis severity using BSI scoring system, had found a statistically significant association between vitamin $D$ levels and BSI scores. This study also found that low vitamin $D$ levels were associated with the disease clinical and radiological severity score. ${ }^{10,26}$ Several studies used a parameter of inflammatory marker in bronchiectasis patients and showed a significant correlation between the two. ${ }^{26}$

The limitation of this study is that not all radiological examination results include the type of bronchiectasis and do not use the Reiff or Bhalla score which serves more detailed description about bronchiectasis lesions. It is important to determine the type of bronchiectasis in assessing the severity of BE. In addition, it is also used to determine Reiff or Bhalla scores. The higher the score, the more severe the radiological severity of bronchiectasis. Therefore, researchers only analyzed vitamin $D$ levels against the number of lobes affected. If further analysis was carried out between vitamin D levels and the severity of bronchiectasis based on reiff or Bhalla scores, it was possible to find a significant association.

\section{CONCLUSION}

There is a positive correlation between low vitamin $D$ levels and the severity of bronchiectasis.

\section{REFERENCES}

1. Seitz $A E$, Olivier $K N$, Steiner $C A$, De Oca RM, Holland SM, Prevots DR. Trends and burden of bronchiectasis-associated hospitalizations in the United States, 1993-2006. Chest. 2010;138(4):944-949.

2. Redondo $M$, Keyt $H$, Dhar $R$, Chalmers JD. Global impact of bronchiectasis and cystic fibrosis. Breathe. 2016;12(3):222-235.

3. O'Donnell AE. Bronchiectasis. Chest. 2008;134(4):815-823.

4. Hill AT, Haworth CS, Aliberti $S$, et al. Pulmonary exacerbation in adults with bronchiectasis: a consensus definition for clinical research. Eur Respir J. 2017;49(6).

5. Pasteur MC, Bilton $D$, Hill AT. British thoracic society guideline for non-CF bronchiectasis. Thorax. 2010;65(SUPPL. 1). 
2008;6(22):195-203.

6. Costa JC, Machado JN, Ferreira C, Gama J, Rodrigues C. The Bronchiectasis Severity Index and FACED score for assessment of the severity of bronchiectasis. Rev Port Pneumol (English Ed. Published online 2018.

7. Yildirim I, Magden K, Hur E. Open Access Clinical Microbiology: Open Access Infection Inflammation and Vitamin D. Clin Microb. 2013;2:4.

8. Foong RE, Zosky GR. Vitamin D deficiency and the lung: Disease initiator or disease modifier? Nutrients. 2013;5(8):2880-2900.

9. Hansdottir S, Monick MM. Vitamin D Effects on Lung Immunity and Respiratory Diseases. Vitam Horm. 2011;86:217-237.

10. Chalmers JD, McHugh BJ, Docherty C, Govan JRW, Hill AT. Vitamin-D deficiency is associated with chronic bacterial colonisation and disease severity in bronchiectasis. Thorax. 2013;68(1):39-47.

11. Bhatta N, Dhakal SS, Rizal S, Kralingen KWV, Niessen L. Clinical spectrum of patients presenting with bronchiectasis in Nepal: Evidence of linkage between tuberculosis, tobacco smoking and toxic exposure to biomass smoke. Kathmandu Univ Med J.
12. Habesoglu MA, Ugurlu $A O$, Eyuboglu FO. Clinical, radiologic, and functional evaluation of 304 patients with bronchiectasis. Ann Thorac Med. 2011;6(3):131-136.

13. Martínez-García MA, De Gracia J, Relat MV, et al. Multidimensional approach to non-cystic fibrosis bronchiectasis: The FACED score. Eur Respir J. 2014;43(5):13571367.

14. Vidaillac C, Yong VFL, Jaggi TK, Soh MM, Chotirmall SH. Gender differences in bronchiectasis: A real issue? Presented at the: 2018.

15. Boyton RJ, Reynolds CJ, Quigley $\mathrm{KJ}$, Altmann DM. Immune mechanisms and the impact of the disrupted lung microbiome in chronic bacterial lung infection and bronchiectasis. Clin Exp Immunol. 2013;171(2):117-123.

16. Quint JK, Millett ERC, Joshi M, et al. Changes in the incidence, prevalence and mortality of bronchiectasis in the UK from 2004 to 2013: A population-based cohort study. Eur Respir J. 2016;47(1):186-193.

17. Malinovschi $A$, Masoero $M$, Bellocchia $M$, et al. Severe vitamin D deficiency is associated with frequent exacerbations and hospitalization in COPD patients. 
Respir Res. 2014;15(1):1-8.

18. Ilyas M, Agussalim A, Megawati M, et al. Relationship between vitamin d level and serum tnf-a concentration on the severity of chronic obstructive pulmonary disease. Open Access Maced $\mathrm{J}$ Med Sci. 2019;7(14):2298-2304.

19. Borekci S, Halis A, Aygun G, Musellim B. Bacterial colonization and associated factors in patients with bronchiectasis. Ann Thorac Med. 2016;11(1):55-59.

20. Qi Q, Li T, Li JC, Li Y. Association of body mass index with disease severity and prognosis in patients with non-cystic fibrosis bronchiectasis. Brazilian J Med Biol Res. 2015;48(8):715-724.

21. Boussoffara $L$, Bouchareb $S$, Boudawara NK, Touil I, Knani J. Nutritional Status in Patients with Non-Cystic Fibrosis Bronchiectasis. Vol 7.; 2018.

22. Suryadinata RV, Lorensia A, Aprilia AP. Profil Vitamin D Pada Pasien Asma dan Non-Asma Dewasa Di Surabaya. Indones J Public Heal. 2017;12(1):106.

23. Widyaswari MS, Zulkarnain I, Indramayu DM. Kadar serum vitamin D (25[OH]D) pada pasien dermatitis atopik. Period Dermatology Venereol. 2016;28(2):11.
24. Pangarapan J, Hubungan S:, Vitamin K, et al. Hubungan Kadar Vitamin $D$ dalam Darah dengan Kejadian Tuberkulosis Paru An Association between Vitamin $D$ levels in Blood and Pulmonary Tuberculosis Cases. J Respir Indo. 2015;35(1).

25. Bartley J, Garrett J, Grant CC, Camargo CA. Could vitamin D have a potential anti-inflammatory and anti-infective role in bronchiectasis? Curr Infect Dis Rep. 2013;15(2):148-157.

26. Ferri $S$, Crimi $C$, Heffler $E$, Campisi $R$, Noto A, Crimi N. Vitamin D and disease severity in bronchiectasis. Respir Med. 2019;148:1-5. 